\title{
Phenological Variation and its Relation with Yield in several Wheat (Triticum aestivum L.) Cultivars under Normal and Late Sowing Mediated Heat Stress Condition
}

\author{
Kamrun NAHAR ${ }^{1)}$, Kamal Uddin AHAMED"), Masayuki FUJITA ${ }^{2)}$ \\ ${ }^{1)}$ Sher-e-Bangla Agricultural University, Faculty of Agriculture, Department of Agricultural Botany, Dhaka-1207, Bangladesh; knahar@sau.ac.bd \\ ${ }^{2)}$ Kagawa University, Faculty of Agriculture, Department of Applied Biological Science, Laboratory of Plant Stress Responses, \\ Miki-cho, Kita-gun, Kagawa 761-0795, Japan
}

\begin{abstract}
Phenological performance in relation to yield of five modern varieties of wheat 'Sourav', 'Pradip', 'Sufi, 'Shatabdi' and 'Bijoy' were evaluated under two growing environments; one is normal growing environment (sowing at November 30) and the other is post anthesis heat stressed environment (sowing at December 30). In case of late seeding, the varieties phased a significant level of high temperature stress that also significantly affected the required days to germination, booting, anthesis, maturity of all varieties including the yield as compared to normal sowing treatment. The temperature during the grain filling or grain maturing period was near $23^{\circ} \mathrm{C}$ in case of normal seeding and it was near about $28^{\circ} \mathrm{C}$ to $30^{\circ} \mathrm{C}$ and sometimes reached above this range in the later period of late seeded treatment. In the normal sowing treatment the germination period was lower than the late sowing treatment as during that time the temperature was higher as compared to late sowing condition where temperature was lower. Days to anthesis and booting decreased due to late sown heat stress condition regardless the cultivars. These phenological characteristics under heat stressed condition led the wheat cultivars to significantly lower the grain yield as compared to normal condition. Due to heat stress, the yield reduction was 69.53\% in 'Sourav', $58.41 \%$ in 'Pradip', $73.01 \%$ in 'Sufi', 55.46\% in 'Shatabdi' and 53.42\% in 'Bijoy'.
\end{abstract}

Keywords: heat stress, wheat, phenology, days to maturity, anthesis and grain development

\section{Introduction}

The latest Assessment Report of the Intergovernmental Panel on Climate Change (IPCC, 2007) projects that the global average temperatures in 2100 will be 1.8 to $4.0^{\circ} \mathrm{C}$ higher than the 1980-2000 average. Different phenological stages differ in their sensitivity to high temperature and this depends on species and genotype as there are great inter and intra-specific variations (Wollenweber et al., 2003; Howarth, 2005). Heat stress is a major factor affecting the rate of plant development (Hall, 1992, 2001; Marcum, 1998; Howarth, 2005).

Wheat (Triticum aestivum L.) is an important cereal food crop and it stands first globally in terms of production and acreage (FAO, 1999). Now wheat occupies the second place in terms of grain production in Bangladesh (BBS, 2008) and its area is increasing consistently every year (BBS, 2008), although its yield is low $\left(1.90\right.$ tha $\left.^{-1}\right)$ as compared to the yield of other wheat growing countries in the world (FAO, 1999). However, according to the findings of the research organizations the potential yield of wheat varieties is 4.0-4.5 $\mathrm{t} \mathrm{ha}^{-1}$ (Bari, 1990). Such a wide yield gap between potential yield and actual yield needs to be reduced to improve the food situation of the country. The reason of low yield may be due to the lack of aware- ness among the farmers about the use of proper agronomic management like variety, sowing time, seed rate, balanced dose of fertilizers and other associated factors of crop production (Quayyum, 1994).

Despite all out efforts made in this direction, yield of wheat is a result of many contributing factors, and among these the time of sowing is an important one and can only be achieved by sowing of wheat crop at its appropriate time. Heat stress due to late sowing beyond certain limits lowers the grain yield significantly. Researchers have pointed out that wheat yield is considerably affected by sowing date (Chio et al., 1992; Liszewski, 1999; Michiyama et al., 1998; Pecio and Wielgo, 1999).

As a tropical country the farmers of Bangladesh are cultivating wheat in winter season. But because of their unconsciousness or to adjust other crop in the same field farmers often go for late planting of wheat. In fact, due to variation of sowing date the ambient temperature vary widely which affects the phenology of any crop plant. Temperature is a modifying factor in all stages including germination, tillering, booting, ear emergence, anthesis and maturity since it can influence the rate of water supply and other substrate necessary for growth (Wanjura and Buxtor, 1972). Under the high temperature, the wheat crop completes its life cycle much faster than under normal temperature 
52

conditions (Fischer, 1985). All crops stages have a short duration, consequently, there are fewer days to accumulate assimilate during life cycle and production of biomass is reduced (Fischer and Maurer, 1976). It ultimately affects grain filling and lastly the yield of crop.

Plant responses to high temperature vary with plant species, varietiy and phenological stages. Reproductive processes are markedly affected by high temperatures in most plants, which ultimately affect fertilization and postfertilization processes leading to reduced crop yield (Wahid et al., 2007). Thus, for crop production under high temperatures, it is important to know the developmental stages and plant processes that are most sensitive to heat stress as well as whether high day or high night temperatures are more injurious. Such insights are important in determining heat-tolerance potential of crop plants. In such context, the study was conducted to see the phonological deviation of five wheat varieties and its relation with yield variation under heat stress condition.

\section{Materials and methods}

The study was conducted at the experimental field of Sher-e-Bangla Agricultural University, Dhaka, Bangladesh during November, 2008 to April, 2009. Geographically, the experimental area is located at $24^{\circ} 75^{\prime} \mathrm{N}$ and $90^{\circ} 50^{\prime} \mathrm{E}$ longitude at the elevation of above $18 \mathrm{~m}$ the sea level. The soil of the experimental pot was siltyloam having noncalcarious properties. The soil of the experimental field belongs to the Shallow Red Brown Terrace Soils. Five modern verities of wheat 'Sourav', 'Pradip', 'Sufi,' 'Shatabdi' and
'Bijoy' were used as experimental materials. Performance of these varieties was evaluated under two growing environments; one is normal growing environment (sowing at November 30) and the other is post anthesis heat stressed environment (sowing at 30 December). The temperature data of the experimental site during the study period have been presented in Fig. 1.

The experiment was conducted in randomized complete block design (RCBD) with three replications. Seeds were sown in $1.5 \mathrm{~m} \times 2 \mathrm{~m}$ sizes plot at rate of $120 \mathrm{kgha}^{-1}$ maintaining $20 \mathrm{~cm}$ line to line and $5 \mathrm{~cm}$ plant to plant distance. Fertilizers were applied in recommended doses and methods. The dose of cowdung was 7 tha $^{-1}$. Urea, triple super phosphate, muriate of potash and gypsum were applied at 180, 140, 40 and $110 \mathrm{kgha}^{-1}$ as a source of N, P, K and $\mathrm{S}$. The whole amount of all fertilizers and manure and two-third urea were applied during land preparation and the rest amount of urea was applied during first irrigation. The first, second and third irrigation was given 20,60 and 80 days after sowing. Weeding and other intercultural operations were done when necessary.

Temperature data were recorded regularly from the field by an automatic maximum and minimum thermometer. Different growth stages of the phenology were observed carefully and recorded accordingly. The grain yield was adjusted at $12 \%$ moisture level.

The data was analyzed using MSTAT-C (Russell, 1994) programme. The mean differences among the treatments were compared by multiple comparison tests using Duncan's Multiple Range Test (DMRT).

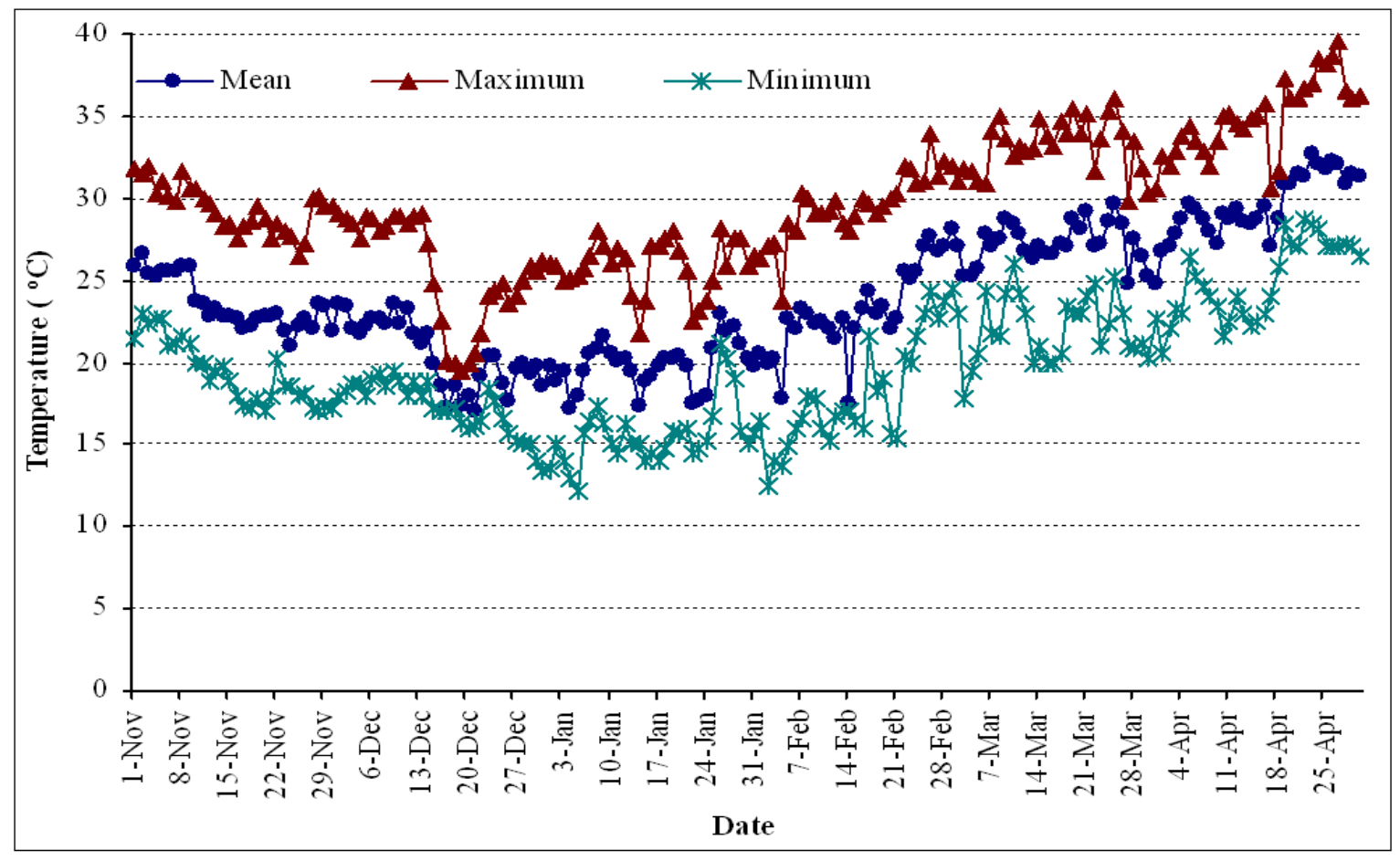

Fig. 1. Maximum, minimum and mean temperature during the experimental period 


\section{Results and discussion}

High-temperature-induced modifications in plants may be clearly understood from the change in existing physiological processes or from the altering pattern of development. These responses may differ from one phenological stage to another. Vulnerability of species and cultivars to high temperatures may vary with the stage of plant development, but all vegetative and reproductive stages are affected by heat stress to some extent (Wahid $e t$ al., 2007).

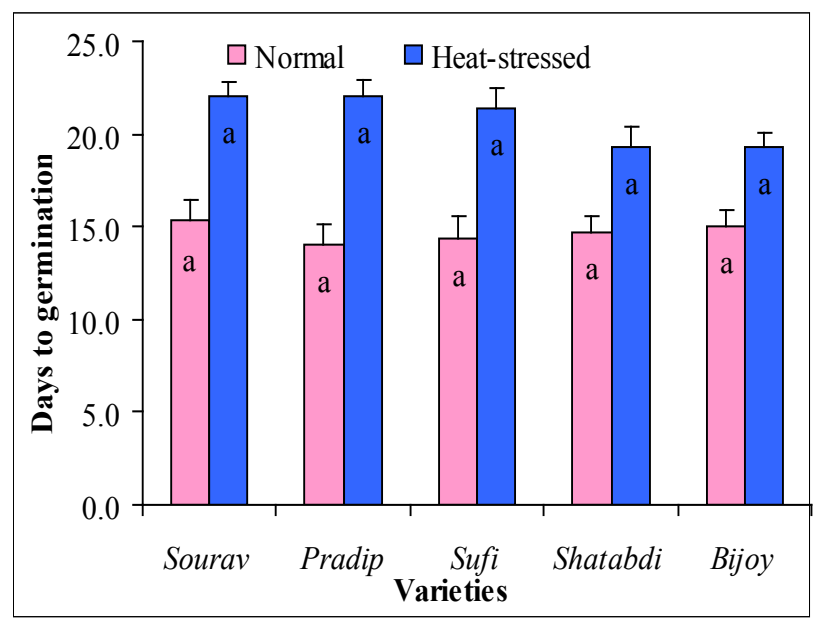

Fig. 2. Differences in days to germination of different wheat varieties under normal and heat stressed condition. Mean $( \pm S D)$ was calculated from three replicates for each treatment. Bars with different letters are significantly different at $P<0.05$ applying LSD test

\section{Germination}

Long-term effects of heat stress on developing seeds may include delaying of germination or loss of vigor, ultimately leading to reduced emergence and seedling establishment Weaich et al. (1996). At preliminary stage, germination of the different varieties took different duration of time. In normal sowing condition, 'Bijoy' and 'Sourav' took more time for germination as compared to others (15.0 and 15.33 days, respectively) and other varieties took more or less 14 days. At late seeding time, 'Sourav' and 'Pradip' took the highest time to complete germination that is 22 days, 'Sufi' took 21.33 days and 'Shatabdi' and 'Bijoy' took the least time for germination (Fig. 2). But no statistical significant difference was found among the varieties in normal and late sowing condition in all the cases in respect to days to germination.

In our experiment, in case of normal sowing (sowing at 30 November) the maximum temperature during germination period was above $25^{\circ} \mathrm{C}$, sometimes near $30^{\circ} \mathrm{C}$ and the minimum temperature was between 15 to $20^{\circ} \mathrm{C}$ (Fig. 1). After 13 December the temperature was gradually de- creasing. After 30 December (i.e. in late sowing condition) the maximum and minimum temperature was near $25^{\circ} \mathrm{C}$ and 12 to $15^{\circ} \mathrm{C}$ with an average temperature of near 17 to $20^{\circ} \mathrm{C}$. If we compare the required time for germination, it is clear that plants with normal sowing time germinate earlier when temperature was higher as compared to late sowing when temperature was comparatively lower (Fig. 2 ). That is high temperature the speed of germination is higher. Sultana et al. (2000) got the similar result and they reported that the maximum germination percentage was 98 at $24^{\circ} \mathrm{C}$. The speed of germination was faster at $29^{\circ} \mathrm{C}$. The most suitable temperature for germination was in the

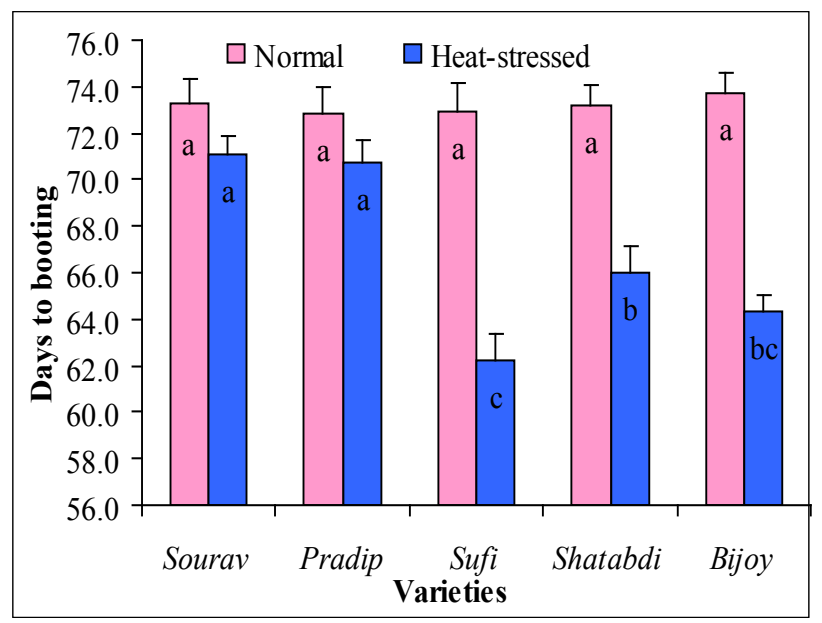

Fig. 3. Days to booting of different wheat varieties under normal and heat stressed condition. Mean $( \pm S D)$ was calculated from three replicates for each treatment. Bars with different letters are significantly different at $P<0.05$ applying LSD test

range of 24 to $29^{\circ} \mathrm{C}$ and with the decrease of temperature germination rate became lower. In the late sowing the ger-

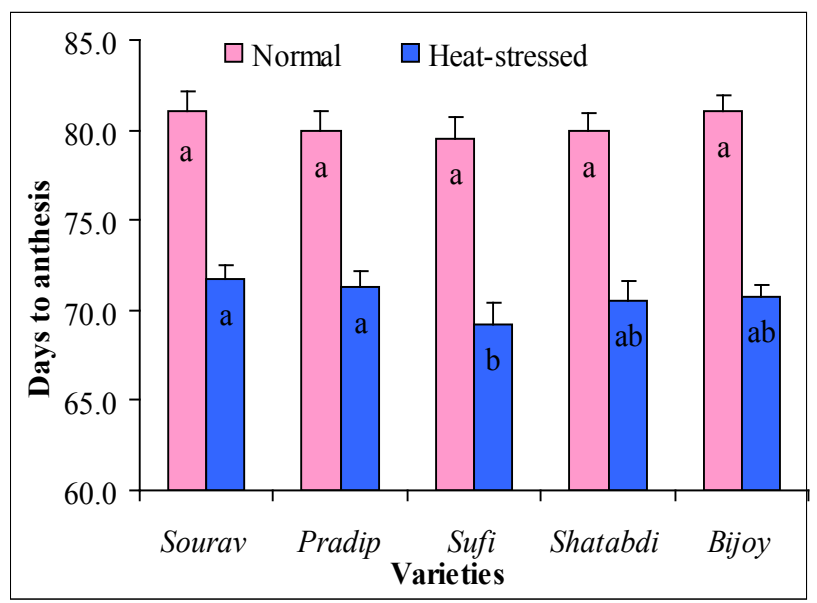

Fig. 4. Days to anthesis of different wheat varieties under normal and heat stressed condition. Mean $( \pm S D)$ was calculated from three replicates for each treatment. Bars with different letters are significantly different at $P<0.05$ applying LSD test 
54

mination period was lower than the normal sowing date. The days requirement for germination increased by $43.5 \%$ in 'Sourav', $57.14 \%$ in 'Pradip', $48.84 \%$ in 'Sufi', $31.76 \%$ in 'Shatabdi' and $28.86 \%$ in 'Bijoy'.

\section{Booting}

Reproductive phases which are most sensitive to high temperature are gametogenesis (8-9 days before anthesis), booting and fertilization (1-3 days after anthesis) in various plants (Foolad, 2005). Both male and female gametophytes are sensitive to high temperature and the response varies with genotypes; however, ovules are generally less heat sensitive than pollen (Peet and Willits, 1998). In normal sowing treatment, all the varieties phased their booting stage between 72 and 73 days and all the values are statistically indifferent. But significant statistical differences were found in late sowing treatment. Due to heat stress booting took less time in late sowing condition. 'Sourav', 'Pradip', 'Shatabdi', 'Bijoy' and 'Sufi' needed 71.07, 70.77, 66.03, 64.37 and 62.2 days for booting, respectively (Fig. 3 ). That means because of late sowing affected high temperature stress days to booting reduced by 3\% in 'Sourav', $2.88 \%$ in 'Pradip', $14.71 \%$ in 'Sufi', 9.79\% in 'Shatabdi' and $12.65 \%$ in 'Bijoy'.

\section{Anthesis}

Under high temperature conditions, earlier heading is advantageous in the retention of more green leaves at anthesis, leading to a smaller reduction in yield (Tewolde et al., 2006). Growth chamber and greenhouse studies suggest that high temperature is most deleterious when flowers are first visible and sensitivity continues for 10-15 days. Among the reproductive phases fertilization (1-3 days after anthesis) is one of the most sensitive stages to high temperature in various plants (Foolad, 2005). In the present experiment, 'Bijoy' (81.03 days) and 'Sourav' (81.1 days) took more time to reach the anthesis stage normally as compared to other varieties ('Shatabdi', 'Pradip' and 'Sufi' took 80.0, 79.93 and 79.5 days, respectively) and statistically their values show no significant difference (Fig. 4). In the high temperature stress condition, the days to anthesis reduced by $11.59 \%$ in 'Sourav', $10.83 \%$ in 'Pradip', $12.95 \%$ in 'Sufi', $11.83 \%$ in 'Shatabdi' and $12.74 \%$ in 'Bijoy'. Under late sowing 'Sourav' required the longest and 'Sufi' required the shortest duration to reach the anthesis stage. Ubaidullah et al. (2006) reported the same findings and observed that generally late sowing imposed negative effects on all the traits. They observed up to 23 days difference between early and late sowing was for heading.

\section{Days to maturity}

It is generally known that the duration of maturity of any crop is reduced by stress condition. High temperature in the post anthesis period shortens the duration of grainfilling (Wiegand and Cuellar, 1981). It was found that for each degree increase of temperature during the grainfilling period it results in about three days decrease in the duration of filling regardless of cultivar (Asana and Williams, 1965). There is a similarity between the others' findings and the present study as in normal sowing condition, 'Shatabdi' took the highest time for maturation (108.0 days) and which was followed by 'Bijoy' (96.67 days). 'Pradip' and 'Sufi' had almost same maturity duration (88.33 and 88.0 days respectively). 'Sourav' had lowest duration (86.33 days) for maturiry (Fig. 5). On the other hand, under late sowing condition, the crop duration was found

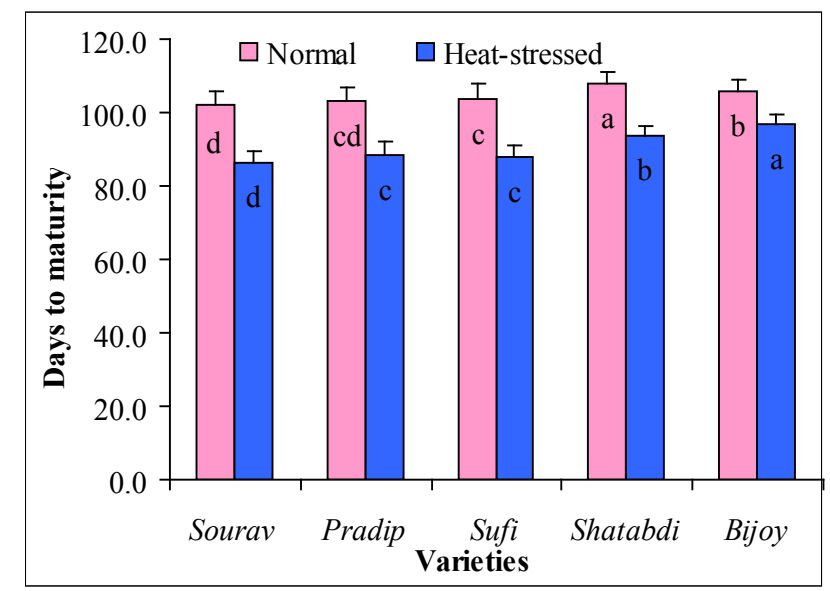

Fig. 5. Days to maturity of different wheat varieties under normal and heat stressed condition. Mean $( \pm S D)$ was calculated from three replicates for each treatment. Bars with different letters are significantly different at $P<0.05$ applying LSD test

the highest in 'Bijoy' (96.67 days) and this is followed by 'Shatabdi' (93.67 days), 'Sourav' (86.33 days), 'Pradip' (88.33 days) and 'Sufi' (88.0 days). The differences in days to maturity among them are statistically significant in case of 'Shatabdi' and 'Bijoy' both in normal and late sowing condition. In case of other varieties 'Pradip' and 'Sufi' are statistically similar in this context and 'Sourav' is different only in the case of late sowing. It can be said that in the high temperature stress condition the days to maturity reduced by $15.61 \%$ in 'Sourav', $14.24 \%$ in 'Pradip', $15.13 \%$ in 'Sufi', $13.26 \%$ in 'Shatabdi' and $8.8 \%$ in 'Bijoy'. There is a similarity between the result of the present study and that of Ubaidullah et al. (2006). It was observed that generally late sowing imposed negative effects on all traits and data showed that minimum difference between early and late sowing was 3 days for grain filling duration whereas and the grain matured 29 days earlier when sown late as compared to the normal sowing time (Asana and Williams, 1965).

In the present study all the varieties matured earlier in late seeding condition as compared to normal seeding. In this experiment, the temperature during the grain filling 
or grain maturing period was near $23^{\circ} \mathrm{C}$ in case of normal seeding and it was about $28^{\circ} \mathrm{C}$ in late seeding condition. Toru and Wardlaw (1988) found that a reduction in grain growth duration and dry matter accumulation rate with increasing temperature above a mean of $26.7^{\circ} \mathrm{C}$. So, result of the present study is similar to the result found by the author.

Wheat cultivars that can fill their grain quickly may have an advantage in environments with short, hot and dry grain filling periods (Whan et al., 1996). So, to avoid the stress condition they complete their life cycle earlier.

\section{Yield}

In tropical climates, excess of radiation and high temperatures are often the most limiting factors affecting plant growth and final crop yield (Wahid et al., 2007). Heat stress, singly or in combination with drought, is a common constraint during anthesis and grain filling stages in many cereal crops of temperate regions. For example, heat stress extended the duration of grain filling with reduction in kernel growth leading to losses in kernel density and weight by up to $7 \%$ in spring wheat (Guilioni et al., 2003).

In our study, 'Bijoy' produced the highest yield (350.6 $\mathrm{g} \mathrm{m}^{-2}$ ) which has statistically significant difference with the variety ('Shatabdi') producing the second highest yield $\left(324.5 \mathrm{~g} \mathrm{~m}^{-2}\right)$ in normal sowing condition (Fig. 6). These two varities also produced the highest yield in late sowing which were 163.3 and $144.5 \mathrm{~g} \mathrm{~m}^{-2}$. 'Sourav' had the lowest yield $\left(285.3 \mathrm{~g} \mathrm{~m}^{-2}\right)$ and 'Pradip' and 'Sufi' produced 314.5 and $312.5 \mathrm{~g} \mathrm{~m}^{-2}$ in normal sowing. But in late sowing the performance of 'Sufi' was the worst and it yielded $84.33 \mathrm{~g}$ $\mathrm{m}^{-2}$.

Hasan (2002) reported that grain yield was found to be reduced by about 2.6 to $5.8 \%$ in heat tolerant and $7.2 \%$ in

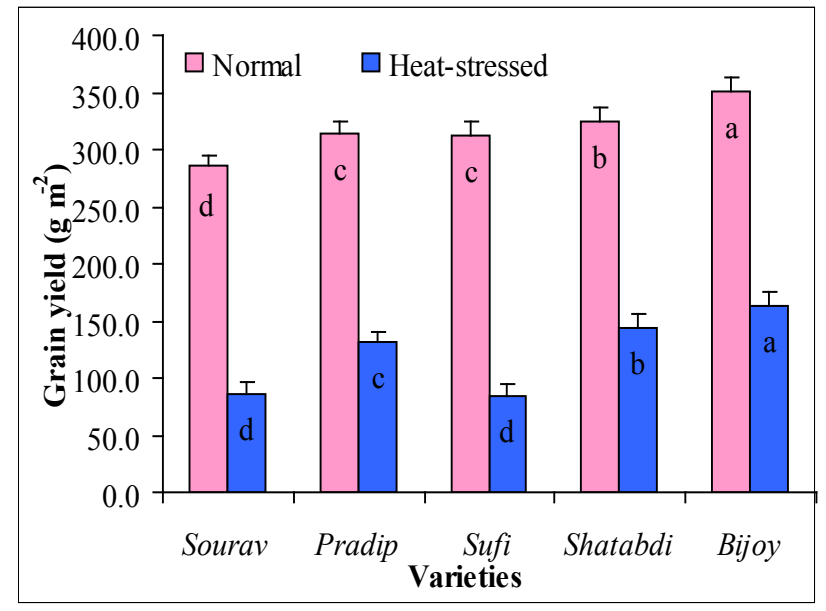

Fig. 6. Yield of different wheat varieties under normal and heat stressed condition. Mean $( \pm S D)$ was calculated from three replicates for each treatment. Bars with different letters are significantly different at $P<0.05$ applying LSD test heat sensitive genotype for each $1^{\circ} \mathrm{C}$ rise in average mean air temperature from normal growing condition during anthesis to maturity. In the present research, in high temperature stress condition the yield reduction was $69.53 \%$ in 'Sourav', $58.41 \%$ in 'Pradip', $73.01 \%$ in 'Sufi', $55.46 \%$ in 'Shatabdi' and $53.42 \%$ in 'Bijoy'. So, the performance of 'Bijoy' was the best in respect of yield as the yield reduction was the least (53.42\%) and it was the worst in 'Sufi' that showed $73.01 \%$ yield reduction.

Among the five experimental materials the variety 'Shatabdi' had the longest maturity period and 'Bijoy' was second after that in normal condition, but during heat stressed period 'Bijoy' had the longer maturity period than the 'Shatabdi' (Fig. 5). The yield of 'Bijoy' was highest both in normal and heat stressed condition (Fig. 6). 'Sourav' and 'Sufi' yielded lowest in both normal and late sowing condition and their maturity durations were also lesser as compared to others. Therefore, it can be said that there is a relationship among the maturity duration and yield of wheat varieties. Sikder et al. (1999) found that in optimum sowing (November 30) the tolerant and sensitive wheat varieties had the similar grain filling duration (40 days) and in December 30 sowing, the tolerant variety had longer grain filling duration (32 days) as compared to sensitive variety ( 28 days). The maturity duration of the variety 'Bijoy' did not reduce due to heat stress so much as compared to others and its yield reduction was also the least among all the varieties. In this context, 'Bijoy' is the best variety amongst all in this experiment and after that 'Shatabdi' is better than the rest varieties and the performance of 'Sufi' is the worst in late sowing heat stress condition. It can also be said that 'Bijoy' has more tolerant to heat stress than all other varieties.

\section{Conclusions}

From the above study, it can be concluded that the heat stress significantly changes the phenology of wheat varieties and the yield as well. Generally due to high temperature stress the stages of life cycle reduce their duration or length. The performance of all varieties is better in all respect in 30, November seeding as compared to 30, December seeding. 'Bijoy' is the best performing variety in heat stress condition as the deviation of phenological stages reduced by the lowest percentage and the yield is the highest among all the varieties. 'Shatabdi' could take place after this. 'Pradip', 'Sourav' and 'Sufi' are the less yielding varieties in heat stress condition.

\section{References}

Asana, R. D. and R. F. Williams (1965). The effect of temperature stress on grain development in wheat. Aust. J. Agric. Res. 16:1-3.

BARI (Bangladesh Agricultural Research Institute) (1990). Annual Rept 1989-90. Bangladesh Agril Res. Inst., Gazipur 
56

p.33-40,

BBS (Bangladesh Bureau of Statistics) (2008). Statistical year book of Bangladesh. Statistics Division, Ministry of Finance and Planning, Government of Peoples Republic of Bangladesh, Dhaka.

Chio, B. H., K. Y. Park and R. K. Park (1992). A study of cultural methods for summer buckwheat sown in spring. Korean J. Crop Sci. 37:149-154.

FAO (Food and Agricultural Organization) (1999). FAO Production Yearbook for the year 1999. Rome, Italy.

Fischer, R. A. and R. Maurer (1976). Crop temperature modification and yield potential in a dwarf spring wheat. Crop Sci. 16:855-859.

Fischer, R. A. (1985). Physiological limitations to producing wheat in semi-tropical and tropical environments and possible criteria. In: R. C. Villareal and A. R. Klatt (Eds.), Wheats for more tropical environments p.209-230. CIMMYT, Maxico, D. F.

Foolad, M. R. (2005). Breeding for abiotic stress tolerances in tomato, p. 613-684. In: Ashraf M. and P. J. C. Harris Eds. Abiotic Stresses: Plant Resistance Through Breeding and Molecular Approaches. The Haworth Press Inc., New York, USA,.

Guilioni, L., J. Wery and J. Lecoeur (2003). High temperature and water deficit may reduce seed number in field pea purely by decreasing plant growth rate. Funct. Plant Biol. 30:11511164.

Hall, A. E. (1992). Breeding for heat tolerance. Plant Breed. Rev. 10:129-168.

Hall, A. E. (2001). Crop Responses to Environment. CRCPress LLC, Boca Raton, Florida.

Hasan, M. A. (2002). Physiological changes in wheat under late planting heat stress. M.S. thesis. Dept. of Crop Botany. Bangabandhu Sheikh Mujibur Rahman Agricultural University. Salna.

Howarth, C. J. (2005). Genetic improvements of tolerance to high temperature. In: M. Ashraf and P. J. C. Harris (Eds.), Abiotic Stresses: Plant Resistance Through Breeding and Molecular Approaches. Howarth Press Inc., New York.

IPCC (2007). Climate Change (2007). The Physical Science Basis. Summary for Policymakers. Contribution of Working Group I to the Fourth Assessment Report of the Intergovernmental Panel on Climate Change.

Liszewski, M. (1999). Response of buckwheat to early planting depending on weather conditions. Folia-Universitatis Agriculturae Stetinensis. Agricultura 79:139-141.

Marcum, K. B. (1998). Cell membrane thermostability and whole plant heat tolerance of Kentucky bluegrass. Crop Sci. 38:1214-1218.

Michiyama, H., A. Fukui and H. Hayashi (1998). Differences in the progression of successive flowering between summer and autumn ecotype cultivars in common buckwheat (Fagopyrum esculentum Moench). Japan J. Crop Sci. 64:498-504.
Pecio, A. and B. Wielgo (1999). Buckwheat yielding and structure of plant and canopy dependent of sowing time. Frag. Agron. 16:5-17.

Peet, M. M. and D. H. Willits (1998). The effect of night temperature on greenhouse grown tomato yields in warm climate. Agric. Forest. Meteorol. 92:191-202.

Quayyum, M. A. (1994). Effect of variety and seed rate on the yield of wheat. Bangladesh J. Agril. Sci. 11:152-153.

Russell, O. F. (1994). MSTAT-C v.2.1 (a computer based data analysis software). Crop and Soil Science Department, Michigan State University, USA.

Sikder, D. S., J. U. Ahamed, T. Hossain, M. A. K. Miah and M. M. Hossain (1999). Membrane thermostability, grain growth and contribution of pre-anthesis stem reserve to grain weight under late seeded condition. Thai J. Agric. Sci. 32(4):465-473.

Sultana, M., M. Hafeez and A. Kashem (2000). Thermotolerance of pearl millet and maize at early growth stages: growth and nutrient relations. Biol. Plant. 48:81-86.

Tewolde, H., C. J. Fernandez and C. A. Erickson (2006). Wheat cultivars adapted to post-heading high temperature stress. J. Agron. Crop Sci. 192:111-120.

Toru, T. and I. F. Wardlaw (1988). A comparison of the effect of high temperature on grain development in wheat and rice. Ann. Bot. 44:53-65.

Ubaidullah, T., M. Raziuddin, S. Hafeezullah, A. Ali and W. Nassimi (2006). Screening of Wheat (Triticum aestivium L.) Genotypes for some important traits against natural terminal heat stress. Pak. J. Biol. Sci. 9:2069-2075.

Wahid, A., S. Gelani, M. Ashraf and M. R. Foolad (2007). Heat tolerance in plants: An overview. Environ. Exper. Bot. 61:199-223.

Wanjura, D. F. and D. R. Buxtor (1972). Hypocotyle and radicle elongation of cotton as affected by soil environment. Agron. J. 64:431-435.

Weaich, K., K. L. Briston and A. Cass (1996). Modeling preemergent maize shoot growth. II. High temperature stress conditions. Agric. J. 88:398-403.

Whan, B. R., G. P. Carlton and W. K. Anderson (1996). Potential of increasing of grain growth in spring wheat I. Identification of genetic improvements. Aust. J. Agric. Res. 57:17-31.

Wiegand, C. L. and J. A. Cuellar (1981). Duration of grain filling and kernel weight of wheat as affected by temperature. Crop Sci. 21:95-101.

Wollenweber, B., J. R. Porter and J. Schellberg (2003). Lack of interaction between extreme high temperature events at vegetative and reproductive growth stages in wheat. J. Agron. Crop Sci. 189:142-150. 